\title{
Process Mapping in a Prototype Development Case
}

\author{
José Dinis-Carvalho $^{1}$, Diana Santos ${ }^{1}$, Mariana Menezes ${ }^{1}$, Melissa Sá ${ }^{1}$, Joana Almeida ${ }^{1}$ \\ ${ }^{1}$ Production and Systems Department, University of Minho, Portugal \\ dinis@dps.uminho.pt, diana_ribeiro_santos@hotmail.com, \\ mariana_meneses_21@hotmail.com,melissa.c.sa.94@gmail.com,joanambpa@gmail.com
}

\begin{abstract}
Process mapping in indirect areas is a powerful tool to increase company awareness of the complete process and allows the identification of problems and improvement opportunities leading to the reduction of lead time, waste as well as improving productivity and competitiveness. In this article a team of students carried out a project in a company aiming to reduce the lead time in the prototype development using a process mapping tool called VSDia (Value Stream Design for Indirect Areas). This tool allowed the identification of several improvement opportunities allowing a reduction of the lead time from 27 to 17 days as well as in productivity gains. This activity also created in the personnel a new awareness of the whole process, the particularities of the process steps and the impact of each process step in other steps of process.
\end{abstract}

Keywords: Process Mapping in Indirect Areas, Value Stream Mapping; Lean Thinking;

\section{Introduction}

The identification of the value and non-value adding steps that are currently required to produce a product or family of products in a production unit is one of the key principles of the lean thinking (Womack \& Jones, 1996). These principles were identified based on the production approach developed by Toyota under the name of Toyota Production System (Ohno, 1988)(Monden, 1998). A very commonly used tool to describe the value and non-value adding process steps (process mapping) in manufacturing environments where lean principles are applied is the Value Stream Mapping (VSM) methodology (Rother \& Shook, 1999)(Jones \& Womack, 2002). In fact the VSM is very often referred as the key methodology in the process of implementing lean and continuous improvement methodologies and approaches. As the lean principles and concepts started to be implemented in non-manufacturing environments such as offices and services, the VSM was also a tool adopted as many books and articles report it. The problem is that the characteristics of nonmanufacturing environments (ex: indirect areas) are not effectively represented using

adfa, p. 1, 2011.

(C) Springer-Verlag Berlin Heidelberg 2011 
VSM since the processing steps are more focused in processing information with very complex routes. Other processing mapping tools were adapted by lean practitioners in different companies when the representation of information processing was necessary. Some used simple tools such as large boards where post-it were placed representing process steps and lines to represent information exchange between process steps.

This article reports a project that was carried out by an Industrial Engineering team of students in a company dedicated to the production of wring systems for heavy machinery. The company identified as a problem the long lead time required in the wiring system prototype process because it can be a competitive factor in the market. The objective of the project was to identify opportunities to reducing that lead time.

\section{Methodology}

Value Stream Design for Indirect Areas (VSDia) (Braga, 2012) (Silva, 2016) is a simple and visual tool to represent broadly a process from the beginning to the end. A process is an organized group of related activities that work together to create a result of value (Browning, Fricke, \& Negele, 2006). In fact, the mapping process is meant to examine the current state of a process and, through its graphical representation becomes apparent which activities that add no value. Thus, it is possible to identify opportunities for improvement and these bases, designing the future state of the process (Nyemba \& Mbohwa, 2017). The methodology applied in this work follows four steps that must be performed sequentially (Silva, 2016).

Phase 1. Preparation - In this step the essential conditions are prepared, in particular a room and the material used to map the current state of the process. In addition, the relevant stakeholders are invited to the meeting at which the expert method clarifies the objectives thereof, sensitizing them to be honest and transparent in the description of tasks.

Phase 2. Value flow analysis - the method applied in this step uses several elements, as can be seen from Figure 1 and is presented below a brief description of each element.

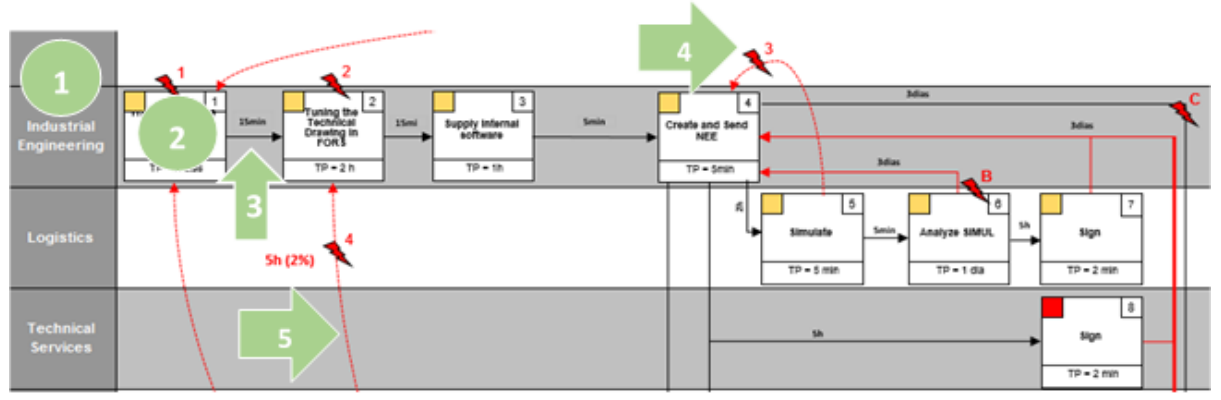


Figure 1 - Mapping Processes

The element 1 refers to tracks or lanes - each track represents an entity or department intervening in the process, may be involved only one person or more.

The element 2 refers to process boxes - each process box contains information about a task carried out by a particular entity, and consisting of the following fields: Sequential numbering of the tasks; task description; task processing time; type of value for the customer. The value for the customer may take one of three colours depending on the value the task is for the customer. Thus, green colour will be assigned to the value-added tasks, yellow to the tasks that add no value but that are necessary and red to those which do not add any value.

The element 3 refers to connectors - they establish a connection between processes. It may include information regarding the transition time between the same, i.e. the time it takes to start a task having been completed the above.

The element 4 refers to flashes - signs that represent problems identified throughout the process. These are numbered and, at the same time, a list with detailed description of the problems and possible improvement solutions is created.

The element 5 refers to queries - they arise whenever it is necessary to go back in the process to complete information that is missing or even correct errors, avoiding the continuation of the process. The queries are represented by dashed red arrows, being accompanied by a flash. In addition, they should also contain information on the frequency with which they occur.

The element 6 refers to temporal elements - refers to the transition time information, and processing queries required to calculate the throughput time. As for the transition time, this is the time that a task is waiting to be processed, after the previous is completed. The processing time is the time delay of a task to be performed. For the query time, this refers to the time spent in question on incomplete information.

Phase 3. Value stream design - refers to the mapping of the future improved process, aiming the following lean principles and concepts:

a) $100 \%$ of value-added activities - any activity that does not add value should be removed from the process. This principle seeks continuous improvement to make the ideal process.

b) Continuous flow of information - activities reverting and processes waiting contribute to waste, so they should be areas for improvement so that the information flow is not interrupted.

c) Parallel processing - activities that have no precedence should be carried out in parallel, and the throughput time reduced.

d) Levelling cadence and workload - tasks need to be standardized so that their processing should be carried out at regular intervals. Another important factor 
has to do with fluctuations in demand, because if significant, should identified as early as possible, enabling proper planning.

e) Customer orientation - customer-oriented tasks should meet as late as possible in the process, but as soon as needed. This prevents that the work derives from outdated information.

f) Ideal capacity - when the capacity is constantly too high or too low and there is the possibility of adjustment it represents waste. Therefore, the capacity should vary depending on the demand.

g) Minimum number of connections between entities - In an ideal state, only one entity should perform a process from start to finish. An effort should be made to select the minimum number of entities really necessary to carry out the whole process, in order to reduce the connections between entities and, consequently, the time spent in the transfer of information.

h) Elimination of rework (Perfect Quality) - incorrect information, incomplete or uncertain will have to be reprocessed. Therefore, measures should be taken on this type of waste to eliminate rework.

i) Customer shaped information - Intermediate documents can be avoided and the information presented in its final form.

j) Elimination of waiting - no process will be delayed due to waiting for approvals, which should be avoided, since they result in waste.

Also according to Tapping \& Shuker (2003), mapping the future state with the suggested changes should take into account three aspects:

a) Customer Requirements: Customer needs should be well understood;

b) Simplicity and transparency: the process should be as simple as possible for employees in order to provide the desired output to the customer (internal / external);

c) Elimination of all mental barriers: all suggestions should be respected even less hypothetical, since they can be beneficial for combination with others.

Phase 4. Implementation - in this last stage standards are developed to implement the measures of the new working method. In order to ensure compliance with the rules, the entities affected by the changes will be trained. Finally, the improvements resulting from this method should be monitored through a checklist designed to determine if the desired performance is achieved. This projects is complete when the performance measures and suggestions for improvement are in fact implemented and running properly.

This methodology can be very effective for improvement but some assumptions have to be guaranteed. The most important one is that the team (at least one person per entity involved in the process) is willing to spend at least half day in a room building the map. This is sometimes difficult because of the incompatibility of 
everyone's schedules as well as the level of priority given to this event. Another important assumption is that everyone is in the right open mind spirit and with a positive attitude towards improvement. It is important to maintain a good relationship between all team members involved during the session. Only in this way they can cooperate and achieve the objectives of this method (Abreu et al., 2017).

\section{Application}

The team in charge of leading the process mapping activity is a team of students from the Integrated Master on Industrial Engineering and Management (University of Minho) carrying out a lean project in this company. One of the student team challenges proposed by the company was to reduce the lead time of new prototype development.

In a first phase, the student team gathered the necessary material for the construction of the map, namely the post-it notes for the tasks, the flashes to identify the problems and improvement opportunities, the paper with large area where the map will be drawn, and pens. Thereafter the paper was placed on a room wall so that the participants would be able to easily visualize the process. To finalize the preparation of the session, a panel was also used to enumerate the flashes and queries describing all the problems encountered in the course of the mapping process. The existence of this panel with the problems described, enhances the visual concept of the tool used, giving opportunity for participants to suggest immediate improvement proposals.

The process mapping event was then scheduled and at the planned time all the following representatives of all entities involved in this process met in the room: Industrial Engineering, Logistics, Technical Services, Quality, Segment 1, Segment 5, Production Engineering, FST (Planning Department), and Packaging and Shipping. This session was led by three students, one responsible for the registration of the problems encountered during the process on the panel and two responsible for leading the mapping process.

Completed the process mapping session, it was possible to understand in detail all the stages of production giving opportunity to the authorities to identify and resolve problems to ensure greater efficiency of processes. The end result of the session can be viewed in Figure 2 showing the final map. In that current state map also shows the part of office operations on the left side of the image and then on the right side the operations that are mainly physical operations. All the problems and improvement opportunities identified were marked on the map with a red flash symbol as shown figure 2 . 


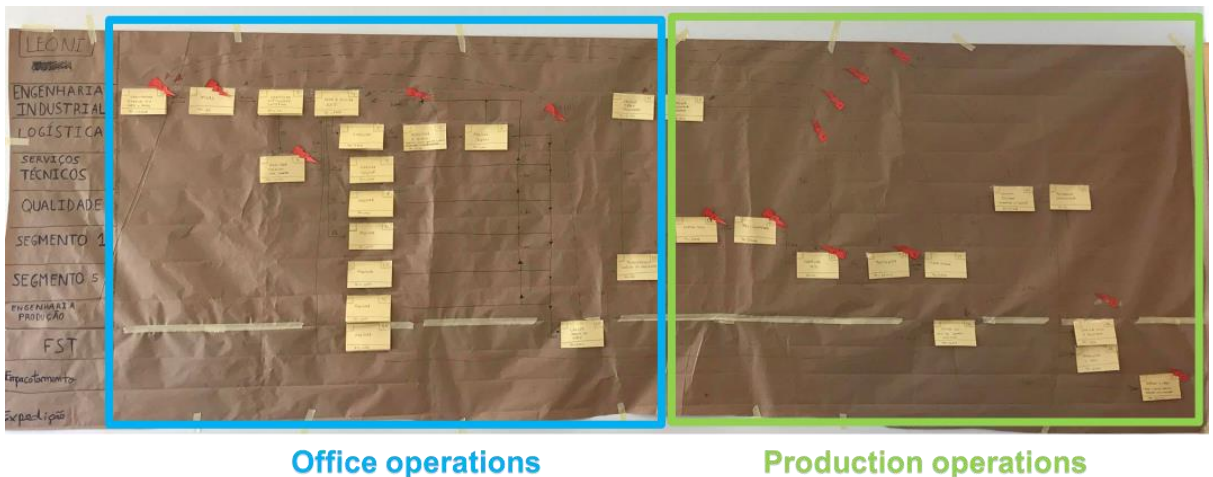

Figure 2 - Process map of the current state

\section{Major improvements}

After the analysis of entire map the discussing was centred in the decision on what problems should be solved first. All problems had to be ranked based on its effect in performance improvement and on the complexity of possible solutions. The selected improvement opportunities are marked in figure 3 and labelled from "Opport 1" to "Opport 5". 


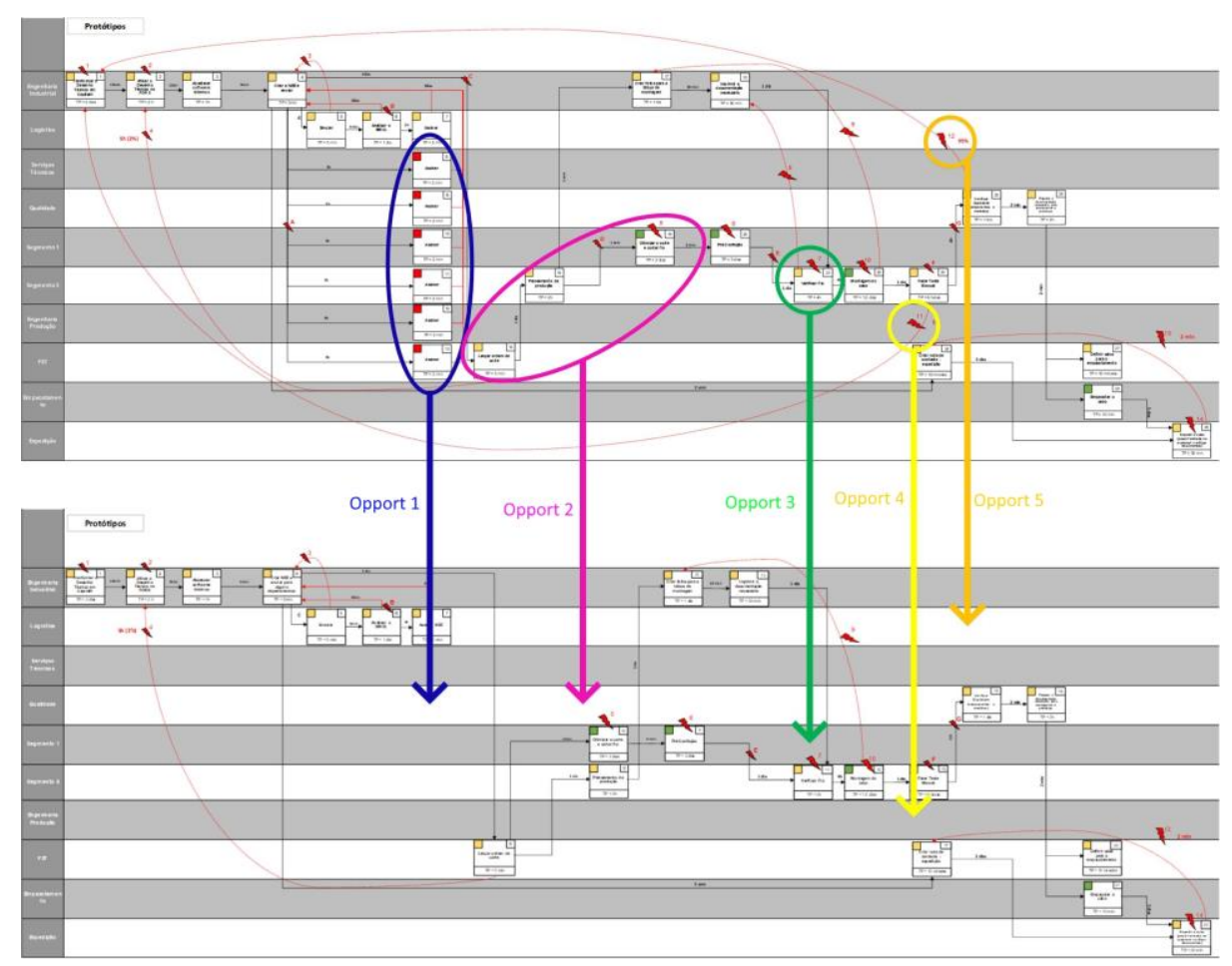

Figure 3 - Main improvements represented in the process map.

\subsection{Opportunity 1 - Reduction of the number signatures}

One of the problems with the highest rank was related to the fact that one document (prototyping order) is nowadays sent to be signed in several departments but in the discussion the team came to the conclusion that the specific document only really needs the signatures of two departments (Industrial Engineering and Logistics), the remaining departments (Technical Services, Quality, Segment 1, Segment 5 and Production Engineering) only need to be informed about the existence of that document.

\subsection{Opportunity 2 - Reduction of the lead time in cable cutting process}

Another interesting opportunity for improvement is that the lead time for cable cutting orders is of one week because for optimization purposes all orders wait until Fridays to be sent to the cable cutting area. The developed proposal is to send wire cutting orders every day as needed so the cut wires could be send next day to the prototype assembly area. This require a daily meeting in the cable cutting area in order to optimize the cutting sequences to reduce setup times. Another improvement that makes sense to be taken in consideration in the cutting process in the future is a lean activity dedicated to the reduction of setup times in the cable cutting machines. 


\subsection{Opportunity 3 - Reduction of the lead time in manual test}

After the assembly of the prototype all wires (several hundreds of wires) must go through a manual test. The worker must verify if the components of each one of the wires in the prototype follow the customer specifications. The worker must identify the reference code of each wire, then search that code in a paper database holding specification for all wires and then compare each wire specification with each wire in the prototype. This operation can take up to 16 hours of work for a single prototype. In order to reduce the operation time as well as the lead time of this quality checking, the proposal includes the introduction of a code scanner as well as a new system that displays in a monitor the respective component characteristics to simplify the task and reduce the operation time.

\subsection{Opportunity 4 and 5 - Code generation for new components}

In the first stages of the process very often the industrial engineering department must generate reference codes for new components. Since this operation takes considerable amount of work and time because it requires communication with the customer to clarify details, they simplify the process creating temporary codes and the process proceeds to next steps. The problem is that only at later stages, when tests quality checks are required, the definite reference codes are needed and the temporary codes must be replaced by them. At those moments the industrial engineering personnel are asked to provide the definite codes as can be represented by flashes associated to "Opport 4" and "Opport 5" represented in top part of figure 3. The new procedure is that the industrial engineering department although letting the process continuing to next stages must start immediately the new reference coding process before the quality check requiring them. There is enough time to create the codes before they are needed at later stages of the process.

\subsection{Other improvements}

Apart from the problems and opportunities identified in the process mapping activities the team also identified other improvement opportunities by observing the production area. This opportunities did not have impact in the prototyping lead time but have impact in the production area productivity. One of the problems was related to the lack of organization in the picking area. Workers had to search for references in a large disorganized shelf without any order. To solve this problem the boxes with wires are arranged in columns properly identified taking into account the sequence of operations to be performed in the pre-confection area. To make this effective organization, the software used by the company should be able to directly locate the box, by adding a parameter "column." This solution simplifies the picker work in finding the box required (see figure 4). 


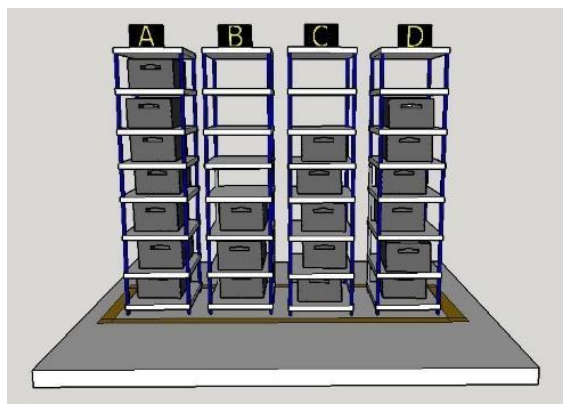

Figure 4. Identification of columns in the picking area.

Another problem was identified in the pre-confection area (responsible to assemble components in wires) where FIFO was not followed. The FIFO was not followed because the boxes were placed randomly on the workstation allowing the workers to select the boxes according to their own interests. Boxes with small batches tended to be left to next shift since the setups are less wanted operation by workers. In order to combat this problem, the logistics should sequence the boxes according to the daily plan provided by this planning system. The plan takes into account the demand of wires in the assembly line as well as minimizing the number of setups when possible. This plan also takes into account a lead time restriction of two days in this area. In order to meet the FIFO, the boxes must be placed on FIFO racks as shown in figure 5 .

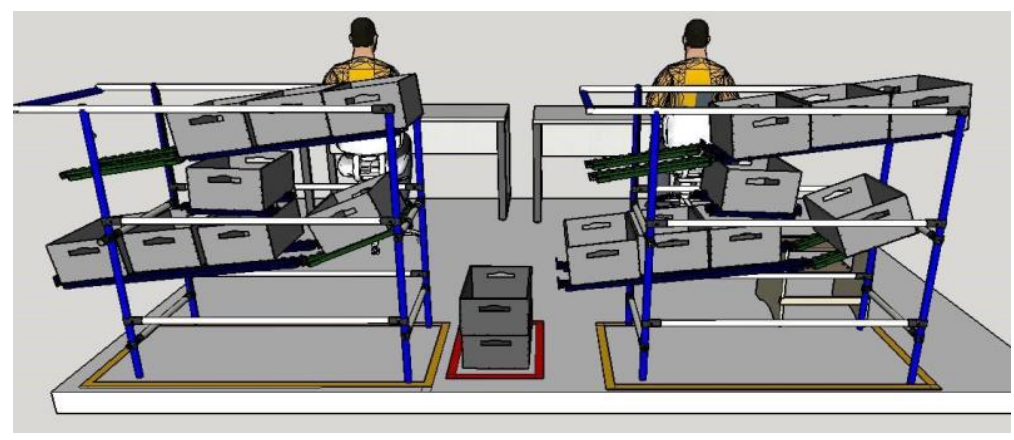

Figure 5. FIFO racks solution.

\section{Results}

The process mapping activities resulted to be a powerful tool in creating awareness among different department's personnel regarding the whole process of prototyping developments. The process mapping session helped to understand others problems that were not understood before. People become aware that some problems can be easily solved by simple understand them and that is achieved by mapping in a large 
board the process steps so everyone can see. This process mapping session resulted in the identification of several improvement opportunities that lead to an immediate lead time reduction from 27 to 21 days in the prototyping development. This reduction derives from the elimination of some signatures that were required for prototyping development order (Opportunity 1 ) and by decreasing the cutting planning time from 5 to 3 days (Opportunity 2).

The other improvements do not have results yet because the implementations are not finished but our estimation is that after fully implementation of Opportunity 3 the lead time can be reduced in one day while the productivity can be doubled. With the new procedure (Opportunity 4 and 5) where the industrial engineering personnel start the generation of new codes before they are asked can lead to an average reduction of 2 days in the lead time.

Finally, the improvements in the picking areas as well as implementation of FIFO lanes in the pre-confection will contribute to a lead time reduction of at least one day in average. The final expected average lead time value in the prototyping process is 17 days, representing 37\% reduction. This reduction represents an impressive improvement in the prototyping development process since the company developed 651 different prototypes in 2017.

\section{Acknowledgements}

This work has been partially supported by projects COMPETE-POCI-01-0145FEDER-007043 and FCT-UID-CEC-00319-2013, from Portugal.

\section{Conclusion}

The objective of this work was to carry out a process mapping activity in the prototype development process in a wire systems company. The activity forced to put all people responsible for each step of the process in the same room building the map. The clarification of the different process steps, its problems and its implication in the whole process, represented a major gain in the organization. This global awareness help in the identification of improvement opportunities as well as the identification of solutions. The solutions already implemented as well as the solution being implemented will lead to a $38 \%$ reduction of the lead time which is of major importance in the market. From the testimonies collected among different players in the company it became clear that no one had a clear picture of the quantity of steps involved in the prototyping generation neither the complexity of some steps or the effect of each step in the whole chain. Some players reported that although feeling that the lead time was large, they did not think it was as large as 27 days. Some people reported that they not know all the stages of the process, or even know of its 
existence in the company. This activity helped in this process of awareness, and the improvements proposed were well accepted and understood by all, due to the fact that now the whole process is known as well as its problems.

\section{$8 \quad$ References}

Abreu, F. M., Pereira, A. C., Silva, A., Silva, F., Ferraz, F., Alves, A. C., ... Vicente, S. (2017). Collaborative Process Mapping to Improve Work Instructions and Standardized Work BT - Recent Advances in Information Systems and Technologies. In Á. Rocha, A. M. Correia, H. Adeli, L. P. Reis, \& S. Costanzo (Eds.) (pp. 603-615). Cham: Springer International Publishing.

Braga, I. (2012). Aplicação do VSDiA para melhoria do processo de cotação na indústria eletrónica. University of Minho. Retrieved from http://hdl.handle.net/1822/22437

Browning, T., Fricke, E., \& Negele, H. (2006). Key Concepts in Modeling Product Development Processes. Systems Engineering, 9, 104-128.

Jones, D., \& Womack, J. (2002). Seeing the Whole. Lean Enterprise Institute, Brookline. Cambridge, MA, USA: Lean Enterprises Inst Inc.

Monden, Y. (1998). Total Framework of the Toyota Production System. In Toyota Production System: An Integrated Approach to Just-In-Time.

Nyemba, W. R., \& Mbohwa, C. (2017). Process Mapping and Optimization of the Process Flows of a Furniture Manufacturing Company in Zimbabwe Using Machine Distance $\begin{array}{llll}\text { Matrices. } & \text { Procedia } & \text { Manufacturing, } & \text { 447-454. }\end{array}$ https://doi.org/10.1016/J.PROMFG.2017.02.057

Ohno, T. (1988). Toyota Production System. International Journal of Operations. https://doi.org/10.1108/eb054703

Rother, M., \& Shook, J. (1999). Learning to see: Value stream mapping to add value and eliminate muda. The Lean Enterprise Institute. https://doi.org/10.1109/6.490058

Silva, A. (2016). Mapeamento do processo de pedido de alterações e implementação de scrum. University of Minho. Retrieved from http://hdl.handle.net/1822/49453

Tapping, D., \& Shuker, T. (2003). Value Stream Management for the Lean Office: Eight Steps to Planning, Mapping, and Sustaining Lean Improvements in Administrative Areas. Civil Engineering (08857024).

Womack, J. P., \& Jones, D. T. (1996). Lean thinking: Banish Waste and Create Wealth in Your Corporation. Productivity Press. https://doi.org/9780743249270 